\title{
Anorectal Amelanotic Melanoma
}

\author{
Akira Hokama $^{\text {a Tetsuya Ohira }}{ }^{a} \quad$ Jiro Fujita ${ }^{b}$ \\ aDepartment of Endoscopy, Graduate School of Medicine, University of the Ryukyus, Okinawa, Japan; \\ ${ }^{b}$ Department of Infectious Diseases, Respiratory and Digestive Medicine, Graduate School of Medicine, University of \\ the Ryukyus, Okinawa, Japan
}

Keywords

Anorectal melanoma $\cdot$ Rectum · Endoscopy

\section{Melanoma anorretal amelanótico}

\section{Palavras Chave}

Melanoma anorectal · Recto · Endoscopia

\section{Case Report}

A 65-year-old man presented with a 3 months' history of hematochezia and anal pain. Digital examination revealed a firm rectal mass. Laboratory examination revealed hemoglobin of $12.9 \mathrm{~g} / \mathrm{dL}$ (normal range, 13.7-16.8 $\mathrm{g} / \mathrm{dL})$. Colonoscopy showed an anorectal tumor involving the distal $3 \mathrm{~cm}$ of the rectum, suggesting adenocarcinoma (Fig. 1). Endoscopic biopsies showed a round cell tumor without melanin pigmentation (Fig. 2a). Immunohistopathological examinations disclosed positive findings for S-100 (Fig. 2b), human melanin black-45 (Fig. 2c), and vimentin (Fig. 2d). A diagnosis of anorectal amelanotic melanoma was made. Computed tomography scans and positron emission tomography images disclosed multiple metastatic lesions in the lungs and liver. The pa-

karger@karger.com www.karger.com/pjg

Karger $\frac{1}{\%}$

GOPEN ACCESS (c) 2020 Sociedade Portuguesa de Gastrenterologia Published by S. Karger AG, Basel

This is an Open Access article licensed under the Creative Commons Attribution-NonCommercial-4.0 International License (CC BY-NC) (http://www.karger.com/Services/OpenAccessLicense), applicable to the online version of the article only. Usage and distribution for commercial purposes requires written permission. tient was informed about chemotherapy options and prognosis of stage IV melanoma but refused undergoing chemotherapy. Best supportive care was offered, and the patient died 4 months later.

\section{Discussion}

Anorectal amelanotic melanoma is an extremely rare disease [1]. As amelanotic melanoma has few melanin granules, it is not easy to differentiate it from various anorectal tumors, such as adenocarcinoma, squamous cell carcinoma, lymphoma, and gastrointestinal stromal tu-
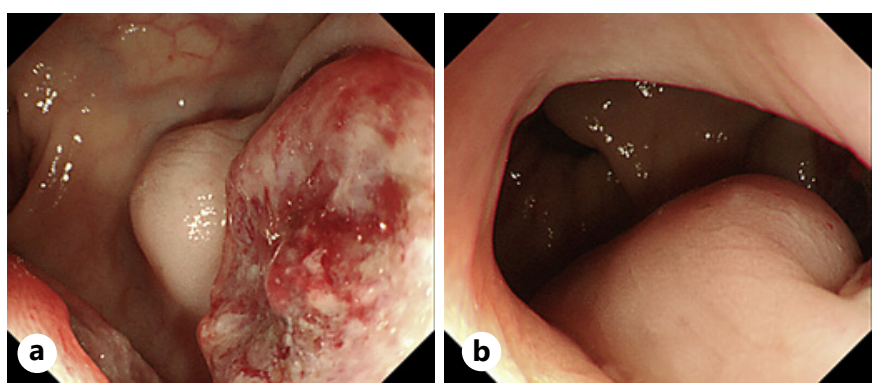

Fig. 1. Colonoscopic images of the tumor. a An ulcerated mass with submucosal invasion in the rectum. b Subepithelial invasion to the anal canal. 
Fig. 2. Histopathology of the anorectal amelanotic melanoma. a Infiltration of round cell tumor without melanin pigmentation. Hematoxylin and eosin. $\times 100 . \mathbf{b}$ Immunohistochemistry of amelanotic melanoma cells. S-100+. $\times 100$. c Human melanin black-45+. $\times 100$. d Vimentin.$+ \times 100$.
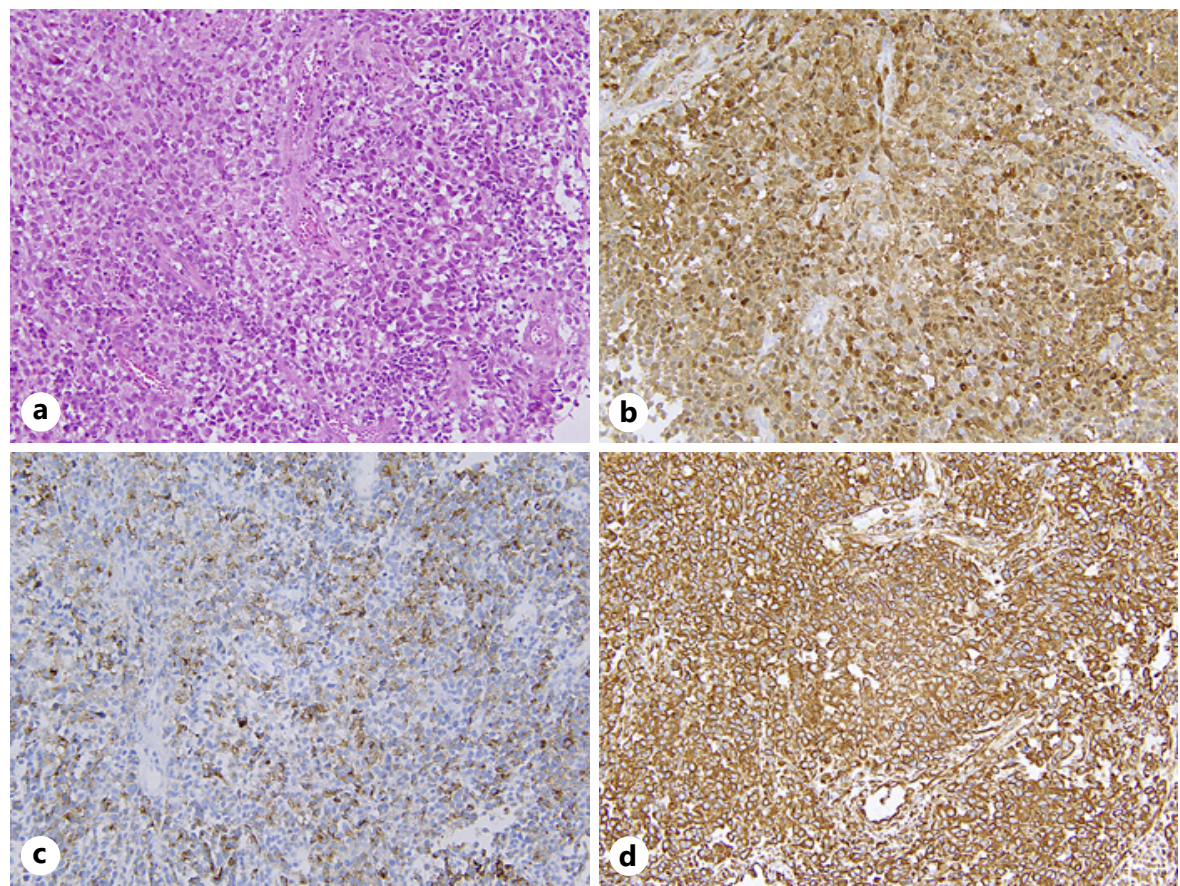

mor. Therefore, immunostaining, as shown in this case, is the key for the definite diagnosis $[1,2]$. The prognosis of anorectal melanoma remains poor, as most cases have lymph node or distal metastasis at the time of diagnosis. Although surgery remains the optimal treatment option, it is regarded as a palliative procedure, making no significant improvement in overall survival [3]. Conventionally, cytotoxic agents, such as dacarbazine and cisplatin, have been applied to stage IV melanoma, with little improvement of prognosis $[2,3]$. Recent development of immunotherapy including immune-check point inhibitors, such as nivolumab and pembrolizumab, have improved the prognosis of this highly lethal malignancy $[2,3]$

\section{Statement of Ethics}

Consent from the patient was obtained for publication. This paper was conducted ethically in accordance with the Declaration of Helsinki.

\section{Conflict of Interest Statement}

The authors have no conflicts of interest to declare.

\section{Funding Sources}

The authors have no funding sources to declare.

\section{Author Contributions}

A.H. performed the endoscopy, obtained the pathological images, and drafted the manuscript. T.O. and J.F. reviewed the paper and approved the final version.

\section{References}

1 Hillenbrand A, Barth TF, Henne-Bruns D, Formentini A. Anorectal amelanotic melanoma. Colorectal Dis. 2008 Jul;10(6):612-5.
2 Tokuhara K, Nakatani K, Tanimura H, Yoshioka K, Kiyohara T, Kon M. A first reported case of metastatic anorectal amelanotic melanoma with a marked response to anti-PD-1 antibody nivolumab: a case report. Int J Surg Case Rep. 2017;31:188-92.
3 Taylor JP, Stem M, Yu D, Chen SY, Fang SH, Gearhart SL, et al. Treatment strategies and survival trends for anorectal melanoma: is it time for a change? World J Surg. 2019 Jul; 43(7):1809-19. 